\title{
Selected papers from the 2015 Workshop on Non-market Valuation (WONV) in Nancy
}

\author{
Serge Garcia ${ }^{1} \cdot$ Pierre-Alexandre Mahieu $^{2}$
}

Received: 23 November 2017 / Accepted: 29 November 2017 /Published online: 18 December 2017

C INRA and Springer-Verlag France SAS, part of Springer Nature 2017

\section{The Workshop on Non-market Valuation (WONV)}

At the beginning of 2012, a small group of economists working on non-market valuation, led by Pierre-Alexandre Mahieu, decided to meet regularly to share their knowledge on valuation methods. The main objectives of this workshop were (i) to provide a forum for dissemination of high-quality papers presenting recent developments in theoretical and empirical analyses in the field of non-market valuation and (ii) to create a network of researchers (including worldwide experts) that would meet every year.

WONV quickly became an annual international workshop. Every year, about 30 researchers meet in a different European city. Both theoretical and applied papers dealing with stated preference methods (e.g., contingent valuation, choice experiments) and revealed preference methods (e.g., travel cost method, hedonic pricing method) are presented. Empirical applications mainly deal with environmental and resource economics but applications to other domains (e.g., health, agriculture) are welcome.

\section{WONV3}

After Nantes and Marseille, the third edition of the workshop (WONV3) was organized by the Laboratory of Forest Economics (LEF INRA/AgroParisTech) in Nancy, 22nd-

Serge Garcia

serge.garcia@inra.fr

Pierre-Alexandre Mahieu

pamahieu@gmail.com

1 Laboratoire d'Economie Forestière, AgroParisTech, INRA, 54000 Nancy, France

2 LEMNA, University of Nantes, Nantes, France 
23rd June, 2015. LEF is one of the leading economic departments in France in nonmarket valuation, especially in relation to the valuation of forest ecosystem services. ${ }^{1}$ The workshop received the scientific support of the European Association of Environmental and Resource Economists (EAERE), which greatly contributed to the visibility of the event. ${ }^{2}$ In addition, it received the support from Environmental Valuation Reference Inventory (EVRI) who gave a free access to the EVRI database to all the participants.

Three keynote speakers were invited to WONV3 to present the most recent advances in their research field: Dr. Brett Day (University of East Anglia, Norwich, UK) on the importance of space in the analysis of revealed preferences (Bateman et al. 2014; Binner and Day 2017), Dr. Stephane Hess (University of Leeds, UK) on choice modeling applied to environmental economics, and Dr. Jurgen Meyerhoff (Technische Universitat Berlin, Germany) on status quo effects in choice experiments (Oehlmann et al. 2017).

A total of 16 papers were selected at the workshop, with participants coming from England, Finland, France, Germany, the Netherlands, and Switzerland. The whole spectrum of non-market valuation approaches was covered although a significant part of the papers relied on choice experiments. In addition, most of the applications dealt with environment or health, although the workshop was not restricted to a given field. Finally, some papers were policy-oriented while others were methodologically oriented. Regarding the latter, many different biases, phenomena, and anomalies were studied, including anchoring effect, hypothetical bias, and consequentiality.

\section{Selected papers}

Many articles could not be included in this issue because they had already been submitted to another journal before the workshop. Today, they have been published in different journals, including the European Journal of Health Economics, Journal of Environmental Economics and Management, Ecological Economics, Applied Health Economics and Health Policy, Journal of Environmental Planning and Management, Environmental Conservation, Water Resource and Economics, and Journal of Forest Economics.

In the following, we briefly describe the three articles that have been selected for this issue of the RAFE. These three papers undertook the usual review process. In a first paper, Nicolas Borzykowski, Andrea Baranzini, and David Maradan assess the recreational benefits of Swiss forests using the travel cost method. The authors use an offsite interview and deal with non-visitors by accounting for their different motivations and behavior in a first-step model of participation. In a second step, they apply a zerotruncated negative binomial approach on the sub-group of forest visitors to estimate travel cost elasticities (representing the demand elasticity for recreation) and consumer

\footnotetext{
${ }^{1}$ Recent publications include the economic valuation of the externalities provided by land uses (especially, forest areas) on the quality of raw water used for drinking water supply (see, e.g., Abildtrup et al. 2013a), the elicitation of recreational users' preferences for forest attributes (Abildtrup et al. 2013b), or the assessment of the value of urban green spaces for local residents (Tu et al. 2016).

${ }^{2}$ Every year, EAERE selects a few workshops or conferences based on their quality. More information on the selection process can be found here: http:/www.eaere.org/content/call-proposals-supported-events.
} 
surpluses for different Swiss forest zones. They find that forest recreation is inelastic to travel cost and that it provides substantial non-market benefits to the population. Moreover, the authors show that the costs associated with forest recreation may be higher than the benefits in some regions.

In a second paper, Léa Tardieu provides a review of the latest advances in the literature on mapping ecosystem services (ES). This review highlights the need for more integrated assessments in the ES mapping literature, which constitute a new research topic. Integrated assessments refer to the treatment of different values (e.g., biophysical, socio-cultural, and monetary), the consideration of several ES and ecosystems, the integration of both spatial and temporal scales, the implication of the different stakeholders, and the combination of different disciplines employing different assessment techniques. According to Scopus, 120 papers related to this theme have been published between 1996 and 2018 with 46 of them published in 2016 and 2017. However, the concept of integrated assessment often describes the combination of very different elements in the literature. A number of challenges still remain to be addressed, from a positive perspective (e.g., potential non-compatibility between biophysical outputs and inputs required in social and economic valuation) and from a normative perspective (e.g., differences in views on the nature of values and on the choice of criteria to prioritize different policy options).

In a third paper, Pierre-Alexandre Mahieu, Henrik Andersson, Olivier Beaumais, Romain Crastes dit Sourd, Stephane Hess, and François-Charles Wolff compare the popularity of contingent valuation and choice experiment by looking at the number of publications and provide a set of references that can be helpful to perform a metaanalysis and a review of literature or to perform benefit transfer studies. More precisely, they have constructed and made available a unique database comprising 1657 choice experiments and/or contingent valuation articles published in journals related to agriculture, environment, or health between 2004 and 2016. They also provide simple statistics and run regression analysis to show that choice experiments are becoming more and more popular in all those fields.

\section{Conclusion}

These three articles have benefited from the comments of the editors and the reviewers, which significantly increased their quality. The results and recommendations emanating from these articles should contribute to increase the quality of the non-market valuation studies, their use for policy making, as well as tractable decision-support tools. With the emergence of economic instruments to regulate market failures, in particular in the domain of environment and the diffusion of Payment for Environmental Services in developing and developed countries, there is a growing need for further valuation studies in order to assess monetary compensations.

Acknowledgement This work was co-financed by a grant from the Lorrain region, France and European Forest Institute. It was also supported by the French National Research Agency (ANR) through the ARBRE Laboratory of Excellence, a part of the Investments for the Future Program(ANR11-LABX-0002-01). 


\section{References}

Abildtrup, J., Garcia, S., Olsen, S. B., \& Stenger, A. (2013a). Spatial preference heterogeneity in forest recreation. Ecological Economics, 92, 67-77.

Abildtrup, J., Garcia, S., \& Stenger, A. (2013b). The effect of forest land use on the cost of drinking water supply: a spatial econometric analysis. Ecological Economics, 92, 126-136.

Bateman, I., Harwood, A., Mace, G., Watson, R., Day, B., et al. (2014). Bringing ecosystem services into economic decision-making: land use in the United Kingdom. Science, 341, 45-50.

Binner, A., \& Day, B. (2017). How property markets determine welfare outcomes: an equilibrium sorting model analysis of local environmental interventions. Environmental and Resource Economics, in press.

Oehlmann, M., Meyerhoff, J., Mariel, P., \& Weller, P. (2017). Uncovering context-induced status quo effects in choice experiments. Journal of Environmental Economics and Management, 81 C, 59-73.

Tu, G., Abildtrup, J., \& Garcia, S. (2016). Preferences for urban green spaces and peri-urban forests: an analysis of stated residential choices. Landscape and Urban Planning, 148, 120-131. 